\title{
University-wide Adoption of Data Science
}

\author{
Debzani Deb \\ Winston-Salem State University \\ Winston-Salem, NC, USA \\ debd@wssu.edu
}

\author{
Elva Jones \\ Winston-Salem State University \\ Winston-Salem, NC, USA \\ jonese@wssu.edu
}

\begin{abstract}
Data Science is an essential concept for twenty-first century workforce and as a result the need to help all students acquire such skill has recently gained increased attention. However, most smaller schools are currently facing challenges to provide related knowledge and skill to a broad student population. During Spring of 2019, we organized a faculty workshop on "Data Science Pedagogy and Practice" aimed at building and enhancing data science capacity (teaching, research, partnership, collaboration) at our institution. We gathered faculty input on what would be needed for a successful university-wide initiative to incorporate data analytics concepts as a basic component of training across variety of disciplines including science, business and social sciences. We were able to identify certain challenges and opportunities to accommodate deeper coverage of data science in the undergraduate teaching and research, and as a result, we initiated few efforts such as 1) teaching through faculty partnership, 2) module-based integration into existing courses rather than developing new courses, 3) development of reusable course modules and augment that with contextual hand-on projects so that students could appreciate the use of data science in their own career path, 4) facilitation of course preparation and implementation via a small faculty adopter grant, and 5) development of a graduate certificate program in data analytics. In this poster, we report our experience in organizing and implementing the workshop, the key aspects of the university-wide data science efforts initiated as a result of the workshop, and the lessons learned so far from these initiatives.
\end{abstract}

\section{CCS CONCEPTS}

Applied computing $\rightarrow$ Education $\rightarrow$ Collaborative learning

\section{KEYWORDS}

Data Science; Curriculum; Computer Science Education

\section{Introduction}

Infusing data literacy into university-wide curriculum is a potential opportunity, specially for smaller colleges, which could significantly impact the current generation of students as they prepare to progress into the workforce. Smaller colleges typically have more flexibility over curriculum, smaller class sizes, more personalized instructions, better faculty-student interactions,

Permission to make digital or hard copies of part or all of this work for personal or classroom use is granted without fee provided that copies are not made or distributed for profit or commercial advantage and that copies bear this notice and the full citation on the first page. Copyrights for third-party components of this work must be honored. For all other uses, contact the Owner/Author.

SIGCSE '20, March 11-14, 2020, Portland, OR, USA

(C) 2020 Copyright is held by the owner/author(s).

ACM ISBN 978-1-4503-6793-6/20/03.

https://doi.org/10.1145/3328778.3372657 more involved administration than the large research-intensive universities, which presents a unique opportunity for them to integrate an exciting and relevant topic such as data science into the curriculum. However, the broader adoption also has numerous challenges such as finding sufficient faculty time and expertise, persuading the higher administration to run an institution-wide effort, building interdepartmental collaborations, providing enough technical support, attracting students from all majors etc.

During Spring of 2019, we organized a day-long faculty (internal only) workshop to explore these opportunities and challenges as a community at Winston-Salem State University (WSSU). The workshop was supported by an NSF award, was participated by 27 faculties representing varieties of departments. The workshop contained invited talk by the representatives from the South Big Data Regional Innovation Hub (https://southbigdatahub.org), one of the four regional Big Data Hubs nationwide, launched by the NSF, and allowed the participants to learn about its initiatives and activities. The workshop also held sessions that helped participants to gain better understanding about data science pedagogy and practice. There were sessions specifically designed to encourage faculty partnership and collaboration in infusing data science into teaching and research. There was a group discussion session following World Café model on building and enhancing data science capacity where the participants were divided into several groups and were given few questions to discuss and to reflect on. The workshop was quite successful in meeting its goals and $100 \%$ of the participants strongly agreed or agreed that attending the workshop is worth their time, $87 \%$ attested that the workshop supported an effective and comprehensive discussion, and $100 \%$ of the participants mentioned that they will actively explore opportunities to infuse data science into their curricula and research. The poster will provide an outline of the workshop, its sessions and outcomes. Our hope is that the others with the same goal of enhancing awareness and collaboration on data science could utilize this model and the workshop resources (http://ibigcloud.altl.org/workshop.html) in order to organize similar event at their institutions. As a result of the recommendations made by the workshop participants, we are currently team teaching four courses in three departments such as Geography, Health Science, and Management and Marketing during Fall of 2019. The poster will contain the initial assessment data gathered on the intervened cohort of students.

\section{ACKNOWLEDGMENTS}

This research was supported by NSF Award \# 1600864.

[1] Wiley, New York, NY. 